Studia UBB 婿igitalia, Volume 63 (LXIII) 2018, December, Issue 2, 51-64

Published Online: 2018-12-30

DOI:10.24193/subbdigitalia.2018.2.04

\title{
Building life courses and explaining life choices with the help of digital prosopography
}

\author{
Vlad Popovici, Rada Varga \\ Babeș-Bolyai University, Cluj-Napoca
}

\begin{abstract}
Digital tools have enhanced the possibilities of historical prosopographic researches, bringing to light facts and connections unnoticed before. Showcasing two very different databases - in structure, timeframe and employed sources we will try to highlight how structured data can prove useful and revealing for the prosopography of the people living in all historical periods and areas. In order to make our point, we will first present the two databases from architectural and technical points of view, then we will focus on case studies extracted from each of them. The aim is to highlight the gain in historical knowledge brought forth by the employment of digital tools and technologies and how these means actually increase our insightfulness when facing the sources.
\end{abstract}

Keywords: historical databases, digital prosopography, life courses, biography, structured data

Digital methods of investigation have opened new perspectives and options in historical research. As methods become methodologies and tools evolve into being designed exclusively and purposefully for humanistic researches, historians have found the possibility to open new doors to the past and make their investigations more insightful, based on an unprecedented exhaustiveness in the use of sources.

In her 2000 article from History and Computing, dr. Katharine Keats-Rohan, maybe the most important "re-founder" of historical prosopography, stated that prosopography is about what the analysis of the sum of data about many individuals can tell us about the different types of connection between them, and hence about how they operated 
within and upon the institutions—social, political, legal, economic, intellectual-of their time. It is hard to imagine a better-adjusted definition, comprising all the complexity and interconnectivity implied by this type of researches. One may easily notice the use of terms emphasizing the quantitative dimension of prosopographic research (sum of data, many individuals), projected as steppingstones towards qualitative aims (to be able to differentiate and compare types of connections) in order to understand their functionality (i.e. how they operated) within a given historical society (period of time \& geographic area). Indeed, this is what we are trying to do by constantly building larger and more complex prosopographic databases: ingest information from a plethora of sources, some of them not digitized yet, clean it, ensure a good data linkage and then wait for otherwise harder or impossible to spot connections to be brought to light and enter the scope of our analyses. From this point on the digital gradually fades, replaced by more traditional historical approaches meant to help understand and explain the past.

\section{R1by1 \& HDG}

In order to better highlight this process of translation from digitally organized historical data to improvements in historical knowledge by means of digital prosopography, we have opted for showcasing three case studies, covering completely different historical periods, but dealing with the same issue: reconstructing life courses and life choices based on information spread across multiple sources. They were developed within the framework of two very different projects, both employing a prosopographical approach and making use of its own custom-built database, fitted to the particularities of the historical frame they are focusing on. But before presenting the results, we will briefly present the concept and architecture of each database, in order to familiarize the reader with our working tools.

Romans 1 by 1 (http://romans 1 by $1 . c o m /$, henceforth R1by1) is a population database for the individuals epigraphically attested in classical Antiquity (we are mainly focusing on the Roman Latin provinces, but we also have datasets from Greek Classical and Hellenistic era colonies from the Black Sea area). No doubt, one of the most important advantages, in this case, is the creation of a prosopographical corpus which can be freely used for scientific purposes by anyone interested in the field, as well as for educational purposes, or for disseminating aspects related to ancient history to a wider sector of the public, in an accessible and friendly manner. Another advantage is given by the fact that the database was built in order to be very user friendly and adaptable to the research question one has: more precisely we speak of the search filters in each main category which allow the user to request a specific set of information 
from the database. In this manner, at a click distance, we can find, for example, who all members of private associations were, or who the attested governors of the provinces were. Moreover, all the information of our choice can be easily downloaded in a .xls file and scientifically processed later on.

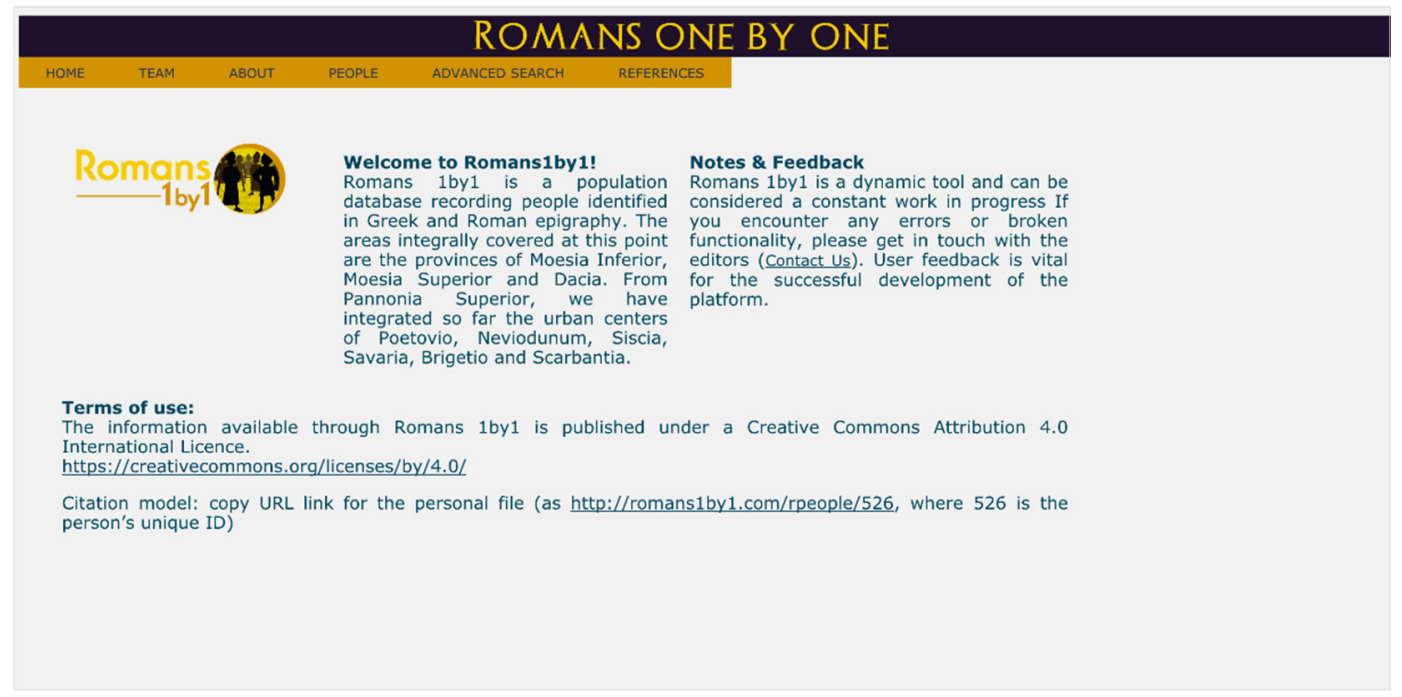

Fig. 1. Romans 1 by 1 website

The database has been documented before (Varga, "Documenting"; Varga, "New Developments"; Varga et al. "Overview"; Varga et al. "Guidebook"), thus we will only schematically present its architecture and the metadata (Fig. 1). Romans 1 by 1 is a relational database, built in MySQL and following the best practice models for population databases (Mandemakers and Dillon). The metadata is structured into four major tables (Inscriptions, Bibliography, Personal Data and Personal relationships - summing up to more than 100 separate attributes) (Varga, "New Developments" 45). The first table to be filled in is the file of the source - Inscriptions; each inscription gets an identification code, formed of five digits and an acronym of the province's name. In this section, certain fields are linked to other existing resources, in order to obtain maximum efficiency for the users. In Bibliography, a normalization table includes all bibliographical titles referred to and being quoted; with the help of a value list, one can choose one Bibliography abbreviation for which the full reference, detailed information and comments are then displayed. Of course, all data are linked to the Inscription code, selected as well from a value list. The core of the database is a table used for recording data about individual persons (labeled Personal data), around which the entire network of relations is built. Each new entry represents a singular epigraphic attestation of an individual, and a unique 
ID is generated, which will help link the character within the various components of the database and with other database entries. The person is also manually linked to the source using a value list of the inscriptions codes. In the case of one person being attested by multiple epigraphic sources, each attestation will be represented by a new entry, to which a new unique ID will be assigned and which will be doubled during linkage procedures by a common ID for all instances of the same person. Expectedly, this metadata is the most volatile one, being in a continuous process of modification and enlargement. As a principle, we are trying to remain faithful to the source and to record during the first phase only the minimum of deduced information. Based on the personal ID given to each individual, the Relationship table will solely name the relationship between individuals (A to B and B to A) (Varga, "New Developments" 50), choosing from a drop-down menu.

Very important for us was the search interface of the database. Built with Rubyon-rails, it was designed to respond to the most manifold and complex search options. Every component of the database has search filters for every particular field, as well as a general search.

Historical Data Grinder (http://hdgrinder.ro, henceforth HDG) ${ }^{1}$ is a database currently hosting information about late $19^{\text {th }}$ century middle classes in Transylvania (by then a part of the Kingdom of Hungary, the eastern half of the Habsburg monarchy), but whose concept was developed having in view a broader aim: to fit an extended range of historical data by employing a modified Entity - Attribute -Value (EAV) architecture. HDG works primarily as a data set aggregator, requiring information to be pre-organized according to its structure, but also allows for continuous addition of piecemeal information or relationships between existing entities directly into the database, through its interface. It was created having in mind the low or medium at best degree of digital literacy of many historians and history students, thus it can easily fit in large datasets imported from common spreadsheet (the widest used method of storing serial data among scholars in humanities), as well as single facts provided by unique sources. It is also designed to accommodate and allow the relationship of information from datasets of extreme diversity created by different authors and covering distinct segments of historical reality, not just $19^{\text {th }}$ century Transylvania from where the research started. In principle, the model can be borrowed for and applied to any type of historical research, regardless of time frame, geography, or thematic approach (Fig. 2).

\footnotetext{
${ }^{1}$ The concept was developed by Angela Lumezeanu and Vlad Popovici. A.L. was in charge of building the database and all associated technical requirements, while V.P. dealt with providing the historical information. The database is part of A.L.'s doctoral project on historical databases in Romania and is currently in testing. An extended description of it will be published soon.
} 


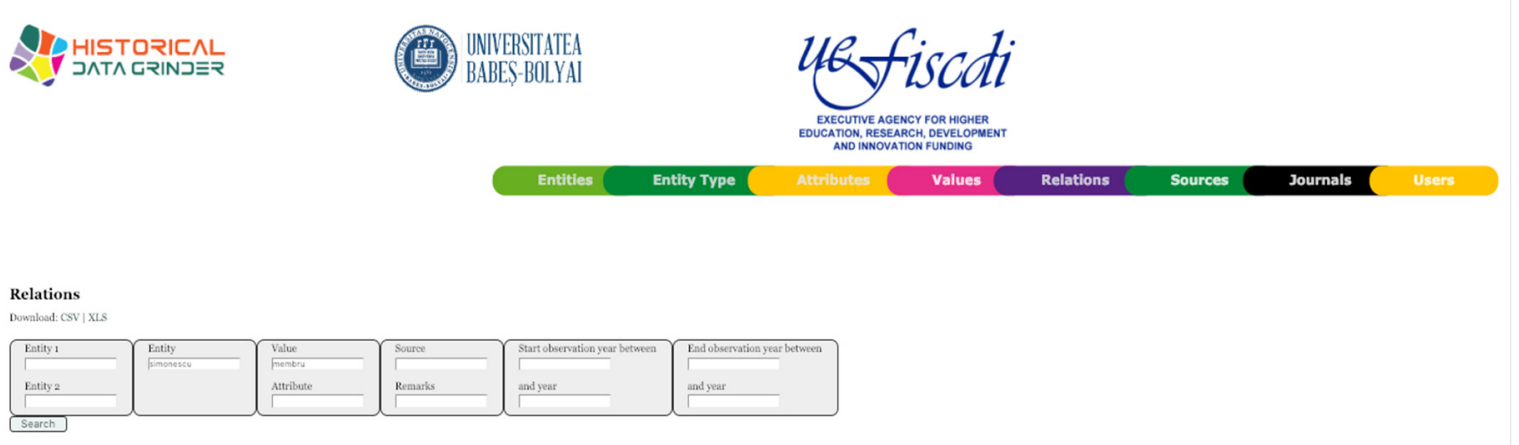

Fig. 2. HDG website

The basic principle behind HDG is that any historical information, from virtually any source, can be grinded down to three basic elements: Entities, Values, and Attributes - the latter including both categories that help order entities and values, as well as a large variety of relations between the aforementioned two. Entities may be: beings (human or animals, real or imaginary), premises and geographical or administrative units, objects or machines, and generally any physical body whose characteristics or activity is recordable, measurable or can be ordered. Values are characteristics of entities, their specificities. A value may be the same for a virtually infinite number of entities (e.g. given height or weight, occupational title, pathological aspects, given area of an administrative unit, technical specs of a machine, etc.). Attributes are general categories that group large sets of values, thus defining the relation between an entity and a value (e.g. "profession" links a person to an occupational title) or as a second possibility they can define the relation between two entities (e.g. "kinship" links two persons; "residence" or "birthplace" link a person to a place).

Following this principle, any given historical information, regardless the form it reaches us can be integrated into an extremely simple and flexible structure of variables. One just needs to carefully assign which type of data goes to which category, namely to properly define what is an entity and what is a value and what type of attribute or relation is associated with them. Timestamps are added to this structure, to help pinpoint the moments in which attributes are being registered, together with information on the sources. The grinded elements can be subjected to analyses or linked to other sources, while the original information from a single source can be at any time recreated with a single command line. 


\section{Roman life courses and expression choices}

The first example is that of an ancient familial and social network, resulted from the conjoining of three Latin inscriptions, well known from the $19^{\text {th }}$ century, but never connected properly, as patterns are not always visible for the naked eye (Varga "Aquila"). Thus, we have a local magistrate (decurio) of a rural settlement and merchant from Potaissa, in northern Dacia, Aurelius Aquila (Fig. 3), who lived during the $2^{\text {nd }} C A D$ and moved at some point of his life to the Dalmatian cost, in Salona (modern day Solin, Croatia); here - and most probably before relocating as well - he worked as a merchant (negotiator). The source we are dealing with is an epitaph, as in Salona he buries his wife, dead after 7 years of marriage without a single quarrel, in a relatively lavish sarcophagus, now lost (It was later published by Th. Mommsen as CIL III 2086). The monument was described by D. Bertolini, Italian archaeologist who, among others, coordinated the excavations from Concordia. In 1885, he saw the monument inside a shop in Venice and described it, but unfortunately it was subsequently lost/destroyed. Nonetheless, Bertolini said that the inscription was part of the 2,25 $\times 0,65$ meters front of a sarcophagus; the area was divided in five registers and the inscription placed centrally. On the sides, there are representations of a Genius and of Mercurius. The author says the reliefs were rudely executed and the monument was generally deteriorated from exposure. The name of Aquila's wife was Valeria Ursina and she was the daughter of Titus, as the inscription states. Another monument (CIL III 2006, curated in the epigraphical collection of the Archaeological Museum of Split), coming from the same city, has the partially damaged name of a father - identified by us with Aurelius Aquila - who dedicates for the memory of his son, Titus Aurelius, a soldier in Pannonia, dead at 33 years old. The soldier bears the second name of Aquila's father-in-law from the sarcophagus, bringing the connection, as well as his maternal lineage, to light. Even if the decurio had in mind to be buried along his wife, he lived for many years on, if we are to consider the second monument. Nonetheless, Apollonius was 33 years old at the time of his death, thus indicating a large interval between the erection of the two monuments - as Aquila and Ursina had been married for seven years, the child must have been very young at the time of his mother's death. This detail makes the lack of a palaeographical comparison less important, as there is a strong chance to deal with different carvers/carving workshops.

But more than this family reconstruction, on the second stone we also have the names of two of Aquila's friends and fellow merchants - thus giving one more relevant clue for the identity of the character. One of them, a Syrian of origin, Aurelius Flavus (Fig. 3), was further on identified on a religious dedication to an Oriental local god from central Dacia. Besides the linkage, the case also brings forth a clear example of disambiguation: 
Flavus bears a name resemblance with another character from northern Dacia, a member of a local elite family from the mid $3^{\text {rd }} \mathrm{CAD}$, with whom he had sometimes been speculatively linked. Now, by linking the two attestations in which his whole title coincides (name + negotians Surus), as well as the circumstances and chronology of his life, we can clearly state that we are dealing with two different characters.

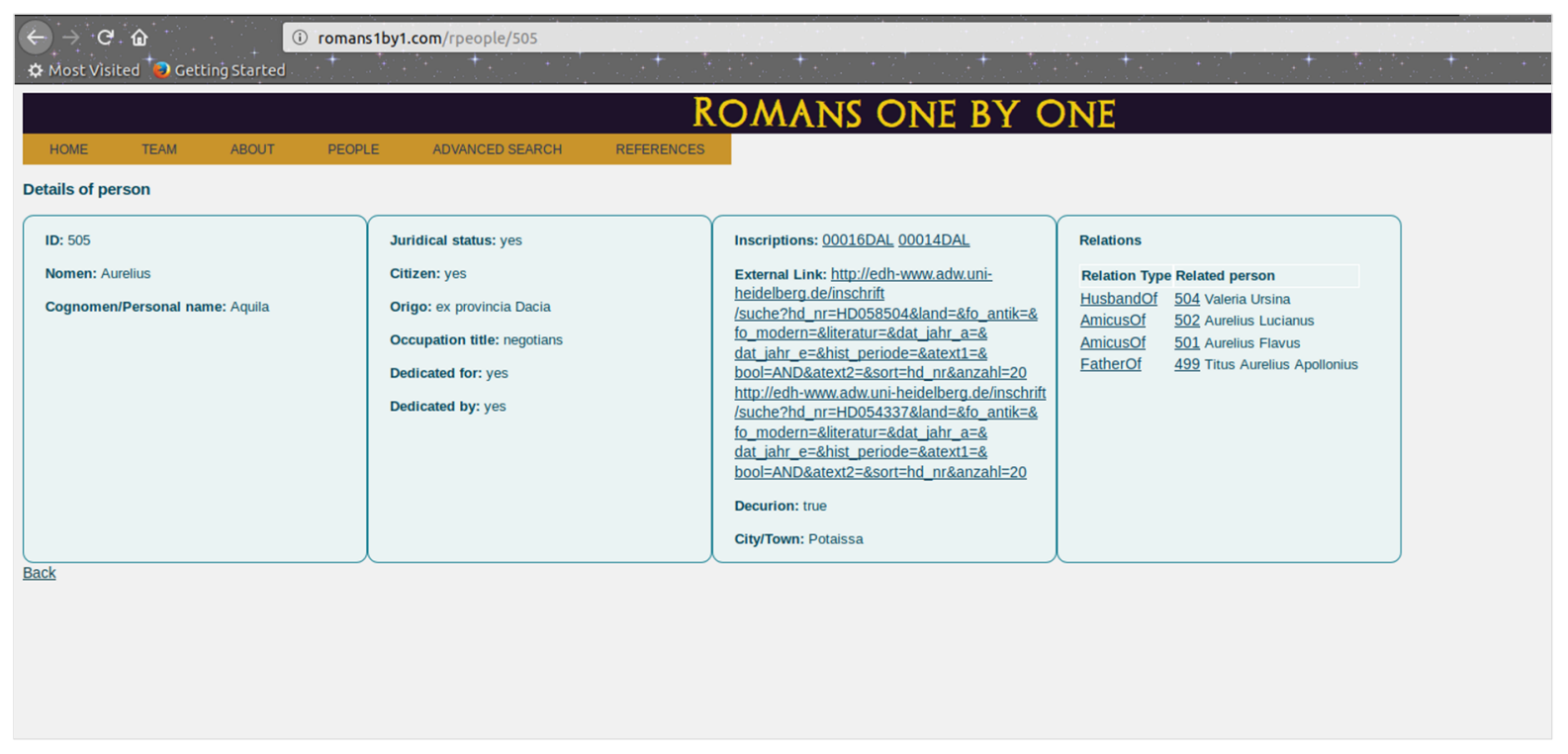

Fig. 3. Personal file in Romans 1 by 1

This small-scale prosopographical reconstruction offers details on the great mobility of traders in the Roman Empire, as well as on how strong and time-enduring business connections could be. By linking the two sources, we gained insight not only into a man's group of work associates and friends, but on commercial and economical routes, on first-hand diffusion of goods and ideas in the ancient world. Generalizing, we can observe patterns of medium/long distance trade, in an age where communications were relatively low and scarce: in the absence of personal identification papers and the possibility of real control, we can assume that impersonal medium/long distance trade was virtually inexistent and personal connections and endorsements were crucial for traders' safety and success. These results were obtained through linkage and disambiguation due to the possibility to query and match all types of biographical data in Romans 1 by 1.

The second case study from Romans1by1 doesn't concern a single person or family, but a professional group - health workers-and a very specific, dual type of epigraphic manifestation: one person explicitly exhibiting profession and origin mark on the same monument. More specifically, out of about 700 independent professionals registered in the Western provinces, a minority (around 100) also lists on their monuments provenience/ 
appurtenance details, such as ethnicity, origo, domus, etc. Our attempt was to reveal the reasons behind this double identification, the connections with the profession in the case of physicians and the socio-psychological background leading to these particular forms of expression.

Table 1. The health workers registering geographical origins on epigraphs

\begin{tabular}{|c|c|c|c|c|}
\hline R1by1 ID & Name & Origo/domus & Profession & Bibliography \\
\hline 2315 & Maximinus Festus & Arelate & pausarius & CIL XII 734 \\
\hline 259 & $\begin{array}{l}\text { Marcus Octavius } \\
\text { Aper }\end{array}$ & Nicomedia & Medicus & AE 1935, 70 \\
\hline 202 & $\begin{array}{l}\text { Marcus Rubrius } \\
\text { Zosimus }\end{array}$ & Ostia & medicus & CIL XIII 6621 \\
\hline 176 & $\begin{array}{l}\text { Caius Iulius } \\
\text { Filetonius }\end{array}$ & Africa & medicus & Tit.Aq. II 656 \\
\hline 251 & $\begin{array}{l}\text { Sextus Pompeius } \\
\text { Carpus }\end{array}$ & Antiochia Syriae & medicus & Tit.Aq. II 684 \\
\hline 389 & $\triangle \mathrm{IOK} \lambda n ́ S$ & Cyzicus & ítpós & ISM I 26 \\
\hline 248 & Aelius Munatius & Samosata & capsarius & $\mathrm{AE} 1906,110$ \\
\hline
\end{tabular}

How does it feel to be the only keeper of important knowledge, of life and death knowledge, from your entourages? Does it feel lonely, is it disconnecting? Today, due to all the information means available, we all hold some basic medical knowledge, we know how the inside of a human body looks like and we more or less understand pathologies and organs functionalities. In the ancient world, the situation was different, a doctor was the only person who had ever seen a dissected body, the only one who had to understand diseases and had to see their various effects. It is fair and justifiable to believe that this created a sense of remoteness, but it might come as a surprise to find out that a certain detachment comes forth, even from the medical personnel epigraphs. Whereas for traders and merchants it all seems to be about connections and people, most of the doctors appear unattached in epigraphs, alone or commemorated by first degree blood relatives. Under these circumstances, it comes as no surprise that few doctors and associated health workers (seven out of 102) write about their origins. But in the few cases when they do, we get places as: Nicomedia, Antiochia Syriae, Cyzicus, Samosata, which are locations of famous medical schools, old and renowned, basically endorsing one's healthcare skills. This is often the only "personal" detail which these inscriptions provide - and it proves it is not personal in fact, but rather a claim of professional legitimacy and competence through belonging. Thus, we have discovered a 
rather surprising consistency with the groups' main epigraphic habit, which would have been mistaken for something else (place of origin) and hard to notice without having the information available in the structured form of a database.

\section{An ordinary bourgeois life course}

Getting closer to our days, the third case study involves a $19^{\text {th }}$ century character: Leontin Simonescu. Despite being a well-regarded member of the Romanian bourgeoisie in Transylvania, highly active in the civil society of the time and former MP in the Hungarian House of Representatives, his biography stirred little interest among Romanian historians. The reasons lie partly in his political career, which took place within the ranks of the Liberal Party (LP) - the government party at the time in Hungary, and the main political adversary of the nationalist Romanian National Party (RNP). Being labelled as "outcast" (the byname for Romanian politicians supporting the Hungarian government before 1918) however, earned him a place in the first, recently published, prosopographical work dedicated to this particular group of several dozen MPs (Iudean 215-218).

No personal archive, no memoires and not a single piece of correspondence by our case study's subject survived. Its three pages-long biographical medallion was written from bits and pieces of information scattered through the press of the time and secondary sources and roughly covers the main aspects of his life and activity. In its creation, the author employed a classical narrative biographical approach. Due to objective limitations of the research (i.e. the high number of research subjects, the discrepancies between them in previous historical interest and the diversity of the sources - mostly not digitized) information scattered in various other sources of the time remained hidden until HDG reunited and linked data from the biographical sketch with serial information regarding the membership and activity of various Romanian institutions from Transylvania in late $19^{\text {th }}$ and early $20^{\text {th }}$ centuries. In what follows we will be reviewing Simonescu's biography, as projected through the lenses of HDG, with the aim of highlighting the benefits of linking serial data with an already existing biographical sketch.

Leontin Simonescu was born in 1840. He studied Law in Vienna and probably Pest, where he was a member of the Romanian students' society and colleague with other future MPs in the Parliament of Hungary, among whom were the brothers Alexandru and Eugeniu Mocsonyi, representatives of one of the most influential Romanian families of the time. During the 1870s he experienced a fast career advance in the administration of Krassó-Szörény / Caraș-Severin county, in south-eastern Hungary (Banat). After reaching the rank of county commissioner (alispán - the highest elected position at county level) he lost it due to the new Lord Lieutenant's need of imposing his own trustee. Immediately 
after, in early 1884 , he decided to run in by-elections for a parliamentary seat in his home constituency, with the program of the LP, which he won fairly easy. However, following this short mandate at the end of the parliamentary cycle 1881-1884, he lost his seat in the summer of 1884 because he was forced to give up running in his home constituency in favour of László Tisza, brother of the Prime Minister Kálmán Tisza. In order to fulfil inner party arrangements, Simonescu had to run for a seat in a neighbouring constituency, where he was defeated by the candidate of the RNP. This was the moment when, probably highly frustrated by this failure, he gave up working with the LP and the Hungarian government and administration and returned to the 'national Romanian' camp. He left his home county and moved to a bigger city, in a relatively neutral position: secretary of the Orthodox Metropolitan in Sibiu / Nagyszeben / Hermannstadt. In the years that followed he clearly experienced an increased involvement in the Romanian associational life, as member and then cashier of the Association for the Culture and Literature of the Romanian People and as an influential lay member of the Orthodox church administration. His son was civil servant in Szeben / Hermannstadt / Sibiu county, one of his daughters married a Hungarian army officer, and the other married Dr. Gheorghe Proca, consistory assessor of the Orthodox Metropolitan in Sibiu. He died there in 1915, and his funeral was conducted by the archimandrite Eusebiu R. Roșca (one of the most influential Romanian church figures of the time) and attended by numerous county officials (ludean 215-218).

All the information in the previous paragraph was provided by the aforementioned biographical sketch. A small part of it was already recorded in HDG (i.e. his positions in the county civil service, his short parliamentary career and unsuccessful candidature, the Astra membership) due to the transfer of information from digital sources such as: the Hungarian yearly civil service directories ("Magyarország" 1873-1918) and the list of Astra's members ("Transilvania" 1900-1919), or from secondary literature (Popovici 75-91, $103-112,135-148,156-167,171-175)$. Although the short biography in itself seems to provide enough information for reconstructing Simonescu's life course, when it comes to understanding and explaining some of his actions and decisions, new data gathered by HDG from other serial sources, unaccounted for by the narrative approach, proves to be essential.

The lists of RNP members between 1881-1892 shows Simonescu (registered as "Leonțiu" instead of "Leontin") has attended the national conference in Sibiu from January 1892, as a representative of Teke / Teaca constituency (Kolozs / Cluj county). This small piece of information does not only pinpoint the continuation of his political activity, but highlights a series of less visible aspects. Firstly, it signals his involvement in the powerplays atop the party and the related networks: failing to be elected as representative of his 
home constituency, he made use of a connection in a remote constituency (which he probably never visited in his life) in order to secure his presence at the conference. Secondly, it raises the question: towards what end wanted Simonescu to be present specifically at this conference given that he showed no interest in the previous ones? The answer lies partly in his biography. In 1892, the party faction headed by his old university colleague Alexandru Mocsonyi, supported by a smaller one gravitating around the Orthodox Metropolitan (his employer) had a hard time maintaining majority in the party board. In this crucial moment Simonescu was probably there in order to help his friends secure the leadership against inner-party opposition - which actually they failed to do (Maior 161-167).

A glance at the board of trustees of the most important Romanian bank in Transylvania ("Albina"), ${ }^{2}$ also brings up Simonescu's name, in relation with some of the most prominent figures of the Romanian society in Sibiu: important members of the Orthodox church administration (Ilarion Pușcariu, loan Hannia, Eusebiu Roșca), high county officials (Ștefan Stroia, loan Crețu), influential freemasons (Aurel Brote) and the vice-president and future president of RNP (George Pop de Băsești) ("Anuarul” 19001919). The data above offers a glimpse at Simonescu's professional networks and it might offer the explanation for his son's relatively fast career in the county administration. According to the civil service yearly directories (currently in the process of transfer into HDG), Alexandru Simonescu functioned from 1905 to 1906 as intern, and from 1907 to 1917 as notary of the orphanage see of Szeben County ("Magyarország" 1905-1918). Thus, it was most probably no coincidence that he occupied the position vacated by loan Crețu, former trustee of "Albina" bank alongside his father. It was also probably no coincidence that Simonescu retired at around the same time from both the position of Astra cashier (1902), and "Albina" board of trustee member (1903), a situation which, even lacking other sources, points in the direction of either health problems or strong disagreements with his colleagues.

Looking back at the evolution of the biographical narrative based on the information from HDG the questions arises: how and to what extent did the employment of a prosopographical database helped historical knowledge and understanding by seemingly minor additions to a person's biography? After all, we are talking in this case about being present at a party conference for one day and being member of a trustee committee for several years (Fig. 4).

\footnotetext{
${ }^{2}$ Currently HDG contains information about the personnel of the ten largest Romanian banks in Transylvania between 1895-1918 and we are constantly working on adding data about new financial institutions based on the banking system yearbooks of the time.
} 
To begin with, the new data was extracted from sources usually lacking a name index, thus hard to approach otherwise in a biographical inquiry. Only a prosopographical approach would justify the effort invested in transferring into a database serial sources covering several decades, which in turn could provide life course information for hundreds of persons.

Still, is this information really useful at an individual level beyond the historian's mere desire of getting to know as many facts from the past as possible? Truth is, the information in itself only gains weight and relevance after being connected with previously known facts about the person's life (e.g. that he was a colleague with A. Mocsonyi, that his son quickly became orphanage see notary, that he retired from various positions at about the same time) and only after being placed into the wider context of the Romanian society and politics of the time. Thus, the real and great benefit of HDG was not providing new information (although this is also a benefit in itself), but making it relevant through connections with the subject's biography and by contextualizing it by means of the whole data gathered and hosted by it.

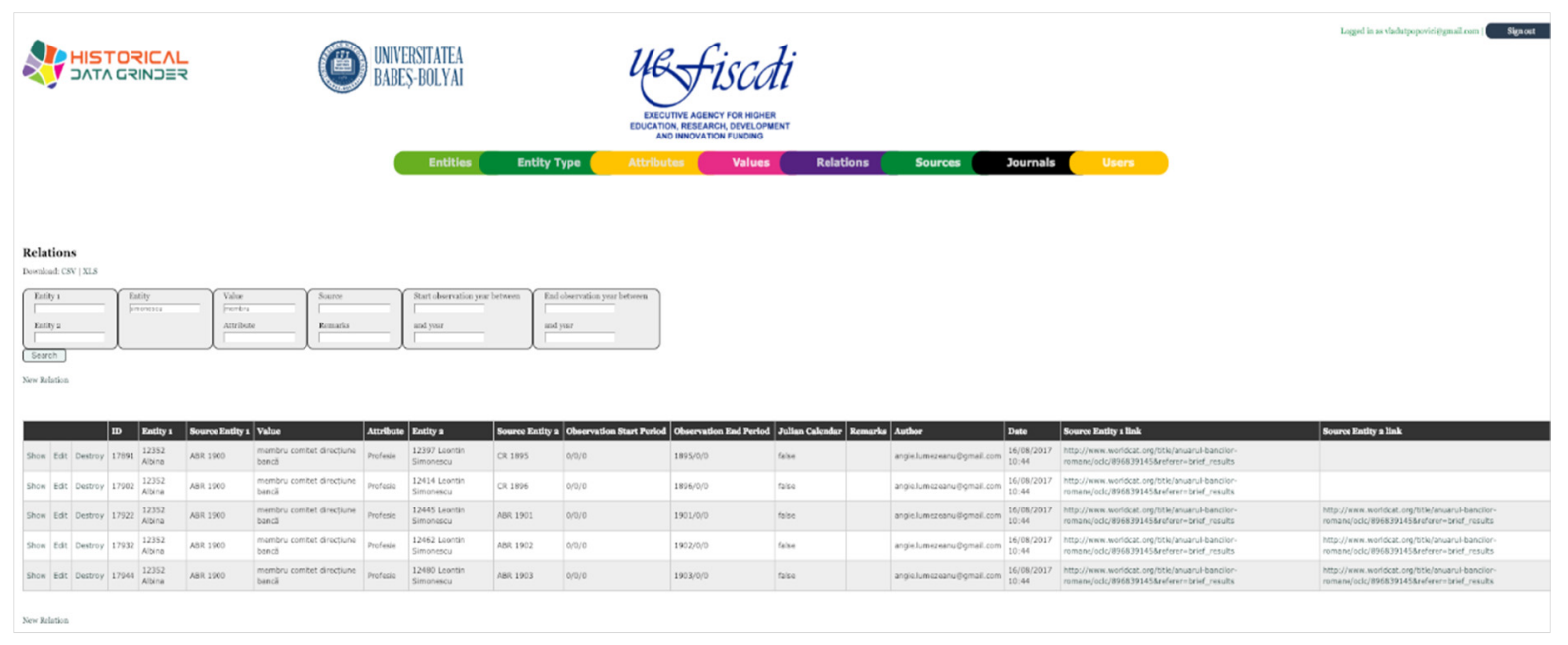

Fig. 4. Person entries in HDG

Furthermore, it is not only the facts and explanations that bear value in this case, but equally the unanswered questions and the hypotheses that sprung up at the point in which jaded facts require fresh data in order to certify and expand their meaning. Through which connection did Simonescu get elected for the party conference in Teke constituency, $175 \mathrm{~km}$ away from home? Is there any other proof, beyond him being colleague with I. Crețu in the trustee board, that he made use of his relations to find a cosy office for his son? What happened in 1902-1903 which made him step down from a series of lucrative positions? 


\section{Conclusions}

The case studies, despite covering completely different historical contexts (which is why they were purposefully chosen in the first place), illustrate the analytical possibilities opened by prosopographical databases when working with information dissipated in various sources, incompletely digitized or just not linked. In the first case the sources have been digitized and could be found in the same epigraphic database, but lacking entity resolution; in the second case the sources are digitized in their original form (scanned newspapers), but they lack proper standardized name indices (given that names are recorded in either Hungarian or Romanian, in different versions for each language) and entity resolution, so identifying an individual and linking him to other datasets is virtually impossible without the use of a database.

Thus, we have concluded that prosopographical databases bring forth advances on three different epistemological levels:

a. by accommodating and linking information from multiple sources, they ease and augment access to knowledge of historical facts, thus helping to recreate more detailed individual life courses which in their turn populate a more vivid historical context;

b. by placing various, seemingly unrelated, facts in a wider context, they allow a better understanding of particular individual life choices, both in relation to one's past and to the societal habits of the moment in which the fact was registered;

c. by ordering and structuring facts they can highlight patterns or similarities with the potential of generating new research question.

To sum up the previously highlighted ideas, the great benefits of digital tools specially designed for a certain type of project/for answering specific research questions lie in the accordingly structured person-records, the very precise querying options and - last but not least - the theoretically correct and complete (not exclusively machine made, but crossed-checked by a scholar who actually understands the historical realities behind the data) aggregation of the necessary sources. In the above-presented cases, piecemeal biographical data allowed the possibility of recreating life courses and more importantly, of explaining life choices when traditional ego-documents and ego-narrativeswhich form the base of traditional historical research—proved to be scarce, parsimonious, or even lack entirely.

\section{Acknowledgements}

This work was supported by two grants of the Romanian Ministry of Research and Innovation, CNCS - UEFISCDI, projects number PN-III-P4-ID-PCE-2016-0390 and PN-III-P4-ID-PCE-2016-0271, within PNCDI III. 


\section{Works Cited}

Anuarul Băncilor Române, vol. II (1900) - XX (1919),

http://dspace.bcucluj.ro/handle/123456789/82910. Accessed January 2019.

Bertolini, Dario. Notizie degli scavi di Antichità. Tipografia della R. Accademia dei Lincei, 1885. ludean, Ovidiu Emil. The Romanian governmental representatives in the Budapest Parliament (1881-1918). Mega, 2016.

Keats-Rohan, Katharine. "Prosopography and computing: a marriage made in heaven?." History and Computing, vol. 12, no. 1, 2000, pp. 1-11.

Magyarország tiszti czim- és névtára, vol. I (1873) - XXXVII (1918),

https://adtplus.arcanum.hu/hu/collection/TisztiCimtar/. Accessed January 2019.

Magyarország tiszti czim- és névtára, vol. XXIV (1905) - XXXVII (1918),

https://adtplus.arcanum.hu/hu/collection/TisztiCimtar/. Accessed January 2019.

Maior, Liviu. Memorandul, filosofia politico-istorică a petiționalismului românesc, Editura Fundației Culturale Române, 1992.

Mandemakers, Kees and Lisa Dillon, "Best Practices with Large Database on Historical Populations." Historical Methods: A Journal of Quantitative and Interdisciplinary History, vol. 37, no. 1, 2004, pp. 34-38.

Popovici, Vlad (ed.). Acte și documente privind elita politică românească din Transilvania 1869-1896. Mega, 2010.

Transilvania, vol. XXXI (1900) - L (1919),

http://documente.bcucluj.ro/web/bibdigit/periodice/transilvania/. Accessed January 2019.

Varga, Rada. "Aurelius Aquila, negotiator ex provincia Dacia. A prosopographic reconstruction." Mensa rotunda epigraphica Napocensis, edited by Radu Ardevan and Eugenia Beu-Dachin, Mega, 2016, pp. 27-34.

Varga, Rada. "Romans 1 by 1 v. 1.1. New Developments in the Study of Roman Population." Digital Classics Online, vol. 3, no. 2, 2017, pp. 44-59.

Varga, Rada. "Romans 1 by 1 . Documenting a Population Database for the Roman World." Digital and Traditional Epigraphy in Context. Proceedings of the EAGLE 2016 International Conference, edited by S. Orlandi, R. Santucci, F. Mambrini, P.M. Liuzzo, Sapienza Università Editrice, 2017, pp. 333-341.

Varga, Rada, Annamária-I. Pázsint, Imola Boda, and Dan Deac. "Romans 1 by 1: Overview of a Research Project.” Digital Classics Online, vol. 4, no. 2, 2018, pp. 37-63.

Varga, Rada, Annamária-I. Pázsint and Angela Lumezeanu. "Romans 1 by 1. A Database Manual." Studia UBB Digitalia, vol. 63, no. 2, 2018, pp. 31-49. 